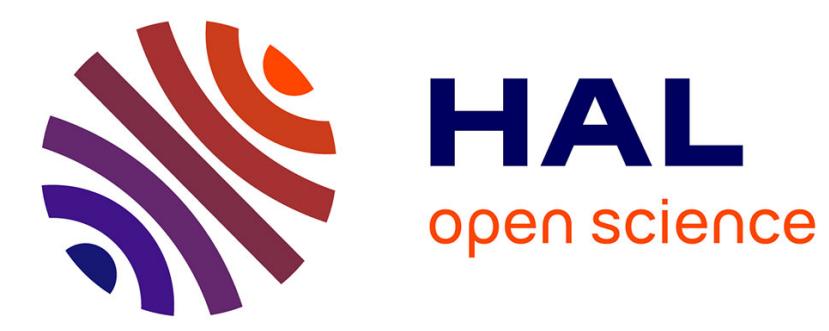

\title{
Social Media Usage of GSM Operators in Turkey: A Content Analysis of Twitter Use
}

\author{
Aysen Temel Eginli, Ozen Okat Ozdem, Isil Karpat Aktuglu
}

\section{To cite this version:}

Aysen Temel Eginli, Ozen Okat Ozdem, Isil Karpat Aktuglu. Social Media Usage of GSM Operators in Turkey: A Content Analysis of Twitter Use. 15th Conference on e-Business, e-Services and eSociety (I3E), Sep 2016, Swansea, United Kingdom. pp.251-260, 10.1007/978-3-319-45234-0_23 . hal-01702186

\section{HAL Id: hal-01702186 \\ https://hal.inria.fr/hal-01702186}

Submitted on 6 Feb 2018

HAL is a multi-disciplinary open access archive for the deposit and dissemination of scientific research documents, whether they are published or not. The documents may come from teaching and research institutions in France or abroad, or from public or private research centers.
L'archive ouverte pluridisciplinaire HAL, est destinée au dépôt et à la diffusion de documents scientifiques de niveau recherche, publiés ou non, émanant des établissements d'enseignement et de recherche français ou étrangers, des laboratoires publics ou privés.

\section{(c)(1)}

Distributed under a Creative Commons Attribution| 4.0 International License 


\title{
Social Media Usage of GSM Operators in Turkey: A Content Analysis of Twitter Use
}

\author{
Aysen Temel Eginli, Ozen Okat Ozdem, Isil Karpat Aktuglu \\ Ege University, Communication Faculty, Izmir, Turkey \\ aysen.temel.eginli@ege.edu.tr \\ Ege University, Communication Faculty, Izmir, Turkey \\ ozen.okat@ege.edu.tr \\ Ege University, Communication Faculty, Izmir, Turkey \\ isil.karpat@ege.edu.tr
}

\begin{abstract}
Social network sites with the increasing importance, take place in the centre of people's life. By the way companies have taken place in social networks for the aim of both to maintain their presence in the virtual environment and also create customer loyalty, improve brand image and customer satisfaction. Recently, Tweeter, has been prefered both companies and customers to transmit the message fast and clearly. Accordingly, this study aims to examine the current state of Turkey GSM Operators' Twitter usage, in the term of passing through $4.5 \mathrm{G}$ (IMT-Advanced) band speed. In addition to this, within the framework of this study focused on the Turkey GSM Operators usage of Twitter as a marketing tool and how do they use it and what do they tweet about in the term of passing through $4.5 \mathrm{G}$ band speed, the content analysis is used.
\end{abstract}

Keywords. information communication technologies, social networks, uses and gratifications theory, social influence network theory, tweeter, customer engagement

\section{$1 \quad$ Introduction}

Within the improvements in the information communication technologies, computer mediated communication has gain importance in people's lives. With social network sites, computer mediated communication has stepped into people's lives expeditiously. Individuals have felt the need to get in touch and communicate online with their families, friends and working environment. In this sense, having an account on social networks and being constantly available have become the most important aspects in daily life practices. Companies can reach their customers fast and inform them about their products and services via social networks, thus the users can retrieve information about services and products of the brands. 
With the effect of social media in 21 st century, changes have been observed in behaviors such as awareness in customer behaviors, purchasing behaviors, post-purchasing behaviors, ideas and attitudes. Social media has become the focal point in consumer to consumer sharing that's why it has become one of the promotional mix elements in terms of marketing efforts.

According to this situation, this study aims to reveal how GSM operators use Twitter, as one of the most technologic companies in Turkey, in terms of informing their customers about the new technology, 4.5G. In this sense, GSM operators made very huge advertising campaigns via conventional media. The campaign has been broadcast throughout the conventional media, and the main purpose of this research is to reveal how the campaign have been represented in social media, especially in Twitter. According to this, social network sites, twitter usage, uses and gratifications theory, and social influence network theory in social media are the bases of this study.

\section{Literature Review}

With the development of Web 2.0 technologies, social communication and therefore community have gained importance. Within this context, concepts of social network, online community and virtual reality have started to gain importance (Jansen et. al, 2009: 2169). Transferring all web-based applications along with social networks into mobile medium both provides constant communication among people, and it also points the characteristic of promoting communication (Tong,2008).

Kaplan and Haenlein (2010:60) defined social media 20 years ago as "Open Diary", which is the oldest form of social network sites. The term was stated as "weblog" when it was first used, later it is defined as "we blog". Social media is a virtual environment that came into existence in order to form social interactions among users with pulling out all the stops. Social media enables its users to speak by providing an opportunity to be in an environment where people want to share ideas at specific subjects without time or geographic restrictions (boyd, 2010). Social media helps consumers make decisions quickly with its user generated content feature (Huang,2010). Baruah (2012:8) points out the advantages of social network sites as follows, sharing of ideas, low cost/ cost effective, less time consuming, bridges communication gap, important marketing tool, important customer interaction tool, important crisis communication tool.

With social media's coming to the fore, communication instruments that companies carry out in their communication strategies with their customers have undergone a change. In this sense, "Social media encompasses a wide range of online, word-of-mouth forums including blogs, company sponsored discus- 
sion boards and chat rooms, consumer-to-consumer e-mail, consumer product or service ratings websites and forums, Internet discussion boards and forums, moblogs (sites containing digital audio, images, movies, or photographs), and social networking websites (Mangold and Faulds, 2009: 358)". In other words, "Social media as a medium of promotion contributes, through its immediacy, to a healthy and direct relation between brands and their public in an online environment (Baruah, 2012:1)”.

Kaplan and Haenlein (2010) have categorized social media as blogs, social network sites (e.g.Facebook), virtual social worlds (e.g.Second Life), collaborative projects (e.g.Wikipedia), content communities (e.g.YouTube), and virtual game worlds (e.g.World of Warcraft). At this point, social network sites put forth the motives and satisfaction related to online media usage as a form of social media.

boyd and Ellison (2007:211) have defined social network sites as "social network sites as web-based services that allow individuals to (1) construct a public or semi-public profile within a bounded system, (2) articulate a list of other users with whom they share a connection, and (3) view and traverse their list of connections and those made by others within the system" and stated that the concept of social network sites refers to public discourse and clarifies the field where people get in touch with others and maintain this connection.

Ellison et. al. (2007) have stated that social network sites offer people a place that they can exist and at the same time, they can create and manage their own social networks and communicate with other people in their online circle. Baruah (2012:8) points out the advantages of social network sites as follows:

- Sharing of ideas: Social network sites provide their users the opportunity of sharing ideas, emotions, thoughts and interests.

- Low Cost/ Cost effective: Using social network sites for perso-nal or business purposes is not only quite cost effective because of its feature of enabling people to reach others simultaneously, but it is also very costefficient.

- Less time consuming: It helps users manage their time effec-tively in terms of reaching and sharing the information needed.

- $\quad$ Bridges communication gap: Social networks enable possibili-ties to share posts on mutual grounds and carry out activities between the people with the same interests by acting as a bridge.

- Important marketing tool: It is an important medium in order for the companies to reach out vast majorities of people on their products and 
services. It also provides convenience to their customers to get feedback on their suggestions and complaints.

- Important customer interaction tool: It creates a very im-portant medium in order to create customer services and to have a one-on-one communication.

- Important crisis communication tool: It is the fastest tool to reach out and to inform the public on occasion of any given cata-strophe or crisis about any corporate, company and/or country.

Twitter has been detected as the most popular social network site according to the number of users. "Twitter is a "social-networking and micro-blogging" service developed in San Francisco and lunched in October 2006" (Tong,2008). Twitter is a system, which was developed to increase text message usage in the beginning of microblogging service year, offers people to send messages by using “@user” syntax. In a sense, it is a new communication platform that has combined social network sites and blogs. "Twitter users follow others or are followed. Unlike on most online social networking sites, such as Facebook or MySpace, the relationship of following and being followed requires no reciprocation" (Kwak et.al.,2010).

In addition to providing communication with other people by creating a profile, Twitter enables its user to send direct messages and allow them to follow other people. Besides, it is also possible to see personal messages and comments in chronological order, as on a blog. Unlike other social media tools, in order to choose a topic and enable its users to follow those topics easily, Twitter uses hashtags (\#), which is the most important feature of it. Also, this feature makes it easy to know the trend topic and analyzing them. Moreover, retweet button, which is used to share someone else's tweets, provide convenience in communication. However, limiting the tweets with 140 characters is usually seen as a restriction regarding the subject that is desired to be shared. Therefore, when people retweet the messages they tend to make some changes in the main messages (boyd, 2010).

Why people use social networks and what do they get by using social media, can be explained with Social Influence Network Theory and Uses and Gratifications Theory. In 1950s and 1960s, usage of mass media tools and which gratifications are created by this usage were defined by analyzing social and psychological variables. Answers to the questions of why people listen to the radio and why do they watch TV were sought. Ruggerio (2000: 27) claimed that the U\&G theory has provided "a cutting edge approach in the initial stages of each new communication medium: newspaper, radio, television, and now the Internet". Katz et.al (1973) explains that motivations and reasons why people choose to use media tools vary between users. 
Uses and Gratifications Theory which explains why people use media tools also guides researchers to explain consumer behaviors and motivations. Explaining why people use social networks, what are the motivations of using them and the gained satisfaction from using social networks can also explain the desire for using the new technological tools. Ancu and Cozma (2009) have stated that social network sites offer "network" that enable its users to create self-presentation profiles and connect to other profiles. Uses and gratifications theory analyzed with computer mediated communication, it is seen that it becomes difficult to make a distinction between needs and motive. Besides, it has been stated that users choose a media tool based on personal preferences and motivations, and "user taste" may differ from person to person and the media tool (Karimi et. al., 2014).

Social influence network theory suggests that people are affected by feelings and thoughts of other people in their networks and they tend to change their feelings and thoughts according to group decisions (Wallach, 2014: 66). The theory was developed by mathematician and social psychologists in the 1950s. The theory explains how network of interpersonal effects have an impact on decision making process based upon formal theory of social power. In 1999, Friedkin and Johnsen have generalized the theory by stating that how effective a network is on sociological work in the formation process of an idea. The theory has 6 elements: Cognitive Weighted Averaging, Fixed Social Structure, Determinism, Continuance, Decomposability.

Social influence network theory shows how interpersonal effects follow a process during the data processing through network. The theory explains how a group of actors' opinions on a subject affect other people. Social networks can be divided into two groups. These groups are affiliation networks, and membership networks or hypernetworks. Also these groups can be defined as affiliation or involvement relation (Hui and Buchegger,2009). Social impacts enable other people to adopt actors' opinions and attitudes, especially in groups, and create a common understanding among the group members or make decisions as a group and even cause them to take part in collective activities together (Friedkin and Johnsen,1999).

Virtual brand organizations founded via social networks and social network websites, have changed consumer behavior of the customers and created new patterns of purchase (Ioanăs and Stoica, 2014). Consumers who consume in the new pattern are exposed to social influence; however, this social influence operates through social networks. These people who use social networks for many purposes such as making friends, obtaining social support also share information and comments about products or services with other people, which makes their decision making process easy and enables them to obtain information about products and services (Kozinets et. al., 2010). 
"Social media marketing consists of the attempt to use social media to persuade consumers that one's company, products and/or services are worthwhile. Social media marketing is marketing using online communities, social networks, blog marketing and more" (Neti,2011: 3). Consumers have control in sending and receiving messages that are about companies and their products. Especially social networks enable customers to share and interactions with other people. In social networks, the relationship between customers are close and profitable(Waad Assaad, 2011). Therefore, the aim of the companies today is to create consumer engagement in social media. At this point, consumer engagement has different components for each customer. The first step to create a consumer engagement is to observe, evaluate, analyze and measure the customers on the social media and take possible actions for the decision making process (Zailskaite-Jakste and Kuvykaite, 2012:195).

Kidd (2011) has stated that in order for companies to establish social media engagement and maintain their relationship with the customers, they need to create an environment that encourages the customers to share their personal histories and express their opinions. Zailskaite-Jakste and Kuvykate (2012) have developed "The conceptual model of consumer engagement in brand equity building in social media" model by using watching, sharing, commenting, producing, curation stages defined by Li and Owyang (2011) to create consumer engagement in social media.

\section{$3 \quad$ Methodology}

This study examined the current state of Turkey GSM Operators' Twitter use, in the term of passing through 4.5G (IMT-Advanced) band speed. The aim of this study is to reveal firstly, whether "Turkey $4.5 \mathrm{G}$ Auction" has an influence on Turkey GSM Operators' Twitter accounts and second - if it yes - to examine how Turkey GSM Operators use Twitter and what they tweet about.

According to the aim, this study is focusing on the following research questions: Do Turkey GSM Operators use Twitter as a marketing tool and if yes, how do they use it and what do they tweet about in the term of passing through $4.5 \mathrm{G}$ band speed?

1. Does the 4.5G Auction in Turkey have an influence on whether Twitter is used or not?

2. Does the 4.5G Auction in Turkey have an influence on the content of Tweets?

3. Does the GSM Operators use Twitter as a marketing tool? 
According to the previous research (Thoring, 2011) the only research method adequate to answer these questions is the content analysis; bearing in mind the analytic aim, a quantitative, standardized approach was chosen.

In Turkey, there are three GSM Operators called, Turkcell, Vodafone and Turk Telekom - Avea. These three operators are persistently competing. As indicated in the literature review, Turkey's GSM internet band speed is 3G. In 27th of August 2015 BTK (Turkey's Information Technologies and Communication Foundation) opened an auction for 4.5G Band Speed. Turkey's three GSM Operators has joined to the auction. The auction was for 20 different frequency package sales. For all packages Turkcell offered 1.63 billion euro, Turk Telekom - Avea offered 954 million euro and Vodafone offered 777 million euro. All three operators bought different megahertz (800, 900, 1800, 2100 and 2600) frequency band packages. This result means a very big enterprise and according to this result, it can be predicted that GSM operators will compete fiercely in marketing area. So, this study focuses on three GSM Operators' tweets after $4.5 \mathrm{G}$ auction.

\section{$4 \quad$ Results}

\subsection{Participation}

The analysis reveals that all GSM operators have at least two Twitter accounts. Turkcell has eight accounts: One of them is @Turkcell, which announces marketing campaigns and this is the main account of the company; @ TurkcellHizmet, which is working as a customer relations; and different accounts for various purposes as @Tcellplatinum, @superonlineTR, @TurkcellMuzik,@TurkcellAkademi,@TurkcellTVPlus,@TurkcellNews.

Vodafone has seven accounts: One of them is @ VodafoneTR, which announces marketing campaigns and this is the main account of the company; @ VodafoneDestek, which is working as a customer relations; and different accounts for various purposes as @VodafoneArena, @VFreeZone, @VodafoneMedya,@VodafoneVakfi,@GeciyorMuyuz.

Turk Telekom and Avea are mergers. At the auction time its name was Avea but now the company called as Turk Telekom. In this study it is considered the last name of the company. As Turk Telekom the company has two original and several fake accounts, so that it has been considered only two original accounts: One of them is @Turk_Telekom which announces marketing campaigns and this is the main account of the company; the other one is @ Galatasaray_TTA, which is about a specific sponsorship campaign.

In this study, only main accounts of company's are considered for the sample. These are,@Turkcell,@VodafoneTR and@Turk_Telekom. 
@Turkcell had joined Twitter in 23rd of August 2007,@VodafoneTR had joined Twitter in 21st of December 2008 and @Turk_Telekom had joined Twitter in 3rd of November 2011. @Turkcell has 602.736 followers, @ VodafoneTR has 606.124 followers, @Turk_Telekom has 307.427 followers in 11th of March 2016. Turk Telekom's follower number is half of the other company's because of its Twitter join date. As being the oldest communication company in Turkey 2011 is very late to join Twitter.

Turkcell has 4301, Vodafone has 35.626 and Turk Telekom has 2068 tweets at all times. Vodafone's huge number of tweets is because of duplication. In the term of analyze, Turkcell tweeted 0,71 , Vodafone tweeted 1,14, Turk Telekom tweeted 0,45 tweet per day.

\subsection{Interactivity}

A users activity on Twitter can be examined by analyzing its Retweets and Replies. Turkcell has 21 retweets and 2 replies; Vodafone has 11 retweets and 85 replies; Turk Telekom has 5 retweets and 8 replies. In the period that tweets were analyzed, $\% 15$ of all Turkcell tweets are retweets, $\% 4,89$ of all Vodafone tweets are retweets, \%5,56 of all Turk Telekom tweets are retweets; $\% 1,3$ of all Turkcell tweets are replies, $\% 37,78$ of all Vodafone tweets are replies and \%8,89 of all Turk Telekom tweets are replies. Reply number reflects direct interaction. According to that statement Vodafone is the most interactive GSM operator account as $\% 37,78$ reply rate.

In the sample Turkcell tweets accounted for $\% 16,42$ of all tweets retweets and replies, Vodafone tweets accounted for $\% 42,6$ of all tweets retweets and replies and Turk Telekom tweets accounted for $\% 14,4$ of all tweets retweets and replies. This result indicates that the most interactive account in the sample is Vodafone, according to its replies and retweets.

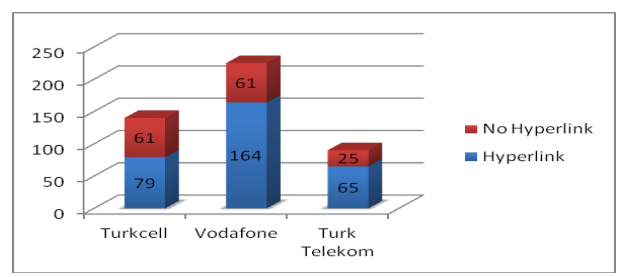

Fig. 1. Categorization by hyperlink

\subsection{Connectivity}

Because of the limited length of Tweets, Twitter - more than other social networking sites and blogs - functions as a distributor which drives traffic to other sites (Thoring, 2011). As seen on figure 1, Vodafone has the maximum 
hyperlink number. According to this result, Vodafone use Twitter mostly as an indicator.

\subsection{Channels of Tweeting}

As seen on figure 2 Of all tweets in the sample most were sent directly on Twitter web page. Turk Telekom used also Android Phone, Tweet Deck, Twitter Ads as a Twitter channel. Turkcell used Twitter Ads and Echofon beside web channel. Vodafone used Twitter Ads, Twitter for iPhone, Periscope and a social responsibility project web page of Vodafone called "DuslerGercekOlsun".

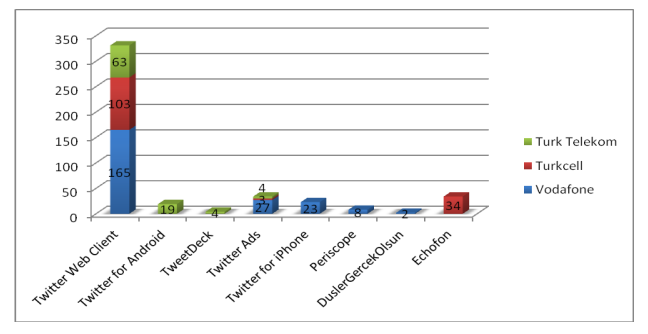

Fig. 2. Channels of tweeting

\subsection{Content of Tweets}

According to the figure 3 Vodafone used Twitter by various contents. The number of "Tweets About Miscellaneous Topics" indicates that result. Also Vodafone used Twitter as a social responsibility projects communication channel. Twitter usage as a marketing tool, nearly same for all GSM operators.

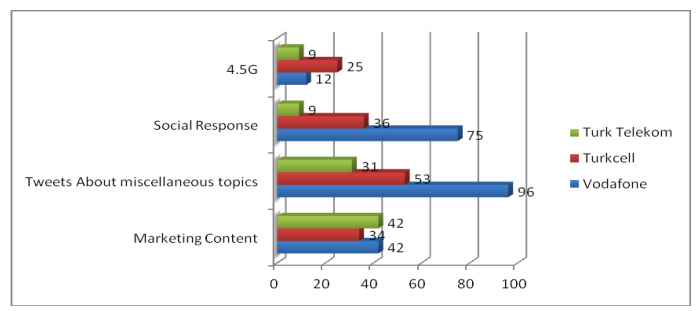

Fig. 3. Content of tweets

According to the research questions, the main aim of this study is analyzing tweets, which are about $4.5 \mathrm{G}$ and marketing content. As seen on figure 4 Turkcell used Twitter as $4.5 \mathrm{G}$ marketing area directly more than the others. 
By of all their tweets, Turkcell used direct / indirect $4.5 \mathrm{G}$ messages $\% 17,85$, Turk Telekom \%10 and Vodafone \%5,3. According to the percentage of tweets, it can be said that Vodafone doesn't use Twitter as a $4.5 \mathrm{G}$ marketing tool. As the money that operators spend for $4.5 \mathrm{G}$ auction, this result is not surprising. The biggest $4.5 \mathrm{G}$ investment is made by Turkcell. As expected, Turkcell has to spend marketing efforts about $4.5 \mathrm{G}$ technology.

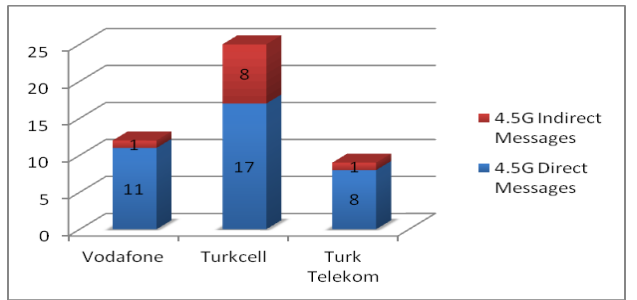

Fig. 4. Tweets by $4.5 \mathrm{G}$ Content

\section{Conclusion}

The aims of this study were, firstly to find out whether "Turkey 4.5G Auction" has an influence on Turkey GSM Operators' Twitter accounts and second - if it yes - to examine how Turkey GSM Operators use Twitter and what they tweet about. As the results, it can be said that there is an influence on Twitter messages even if it is few. As a tweet subject, $4.5 \mathrm{G}$ is seen on Twitter messages. The owner of the biggest investment, Turkcell's number of tweets about $4.5 \mathrm{G}$ is more than the other GSM Operators. Also other GSM operators are investor for $4.5 \mathrm{G}$ technology. As their amount of investment, their tweet numbers about $4.5 \mathrm{G}$ are parallel. GSM operators used $4.5 \mathrm{G}$ content, mostly directly. Also this situation indicates direct marketing messages.

According to the last question of research, it can be said that, as being a profit, GSM operators used Twitter as a marketing tool. Turk Telekom marketing tweets accounted for \% 46,66 of all Turk Telekom tweets. Turkcell marketing tweets accounted for $\% 24,28$ of all Turkcell tweets and Vodafone marketing tweets accounted for $\% 18,66$ of all Vodafone tweets. As this result, nearly half of Turk Telekom's tweets are marketing content.

In Turkey GSM operators made very big campaigns on traditional media. In parallel with it was expected that GSM operators would use social media as traditional media, although the real life doesn't indicate the expected. As ratios, there is a social media usage via Twitter about $4.5 \mathrm{G}$, but the numbers of all tweets are very few. $4.5 \mathrm{G}$ is becoming a technological item, to market it, social media, as a technological media, didn't considered properly as a marke- 
ting tool. May be this because of the internet usage \%49 and Twitter usage $\% 6$ in Turkey.

\section{References}

1. Ancu, M., Cozma, R. : Myspace politics: Uses and gratifications of befriending candidates. Journal of Broadcasting \& Electronic Media, 53(4), 567-583 (2009)

2. Baruah,T.D.: Effectiveness of Social Media as a tool of communication and its potential for technology enabled connections: A micro-level study, International Journal of Scientific and Research Publications, 2 (5), 1-10 (2012)

3. boyd, D. M., Ellison, N. B.: Social network sites: Definition, history, and scholarship. Journal of Computer-Mediated Communication, 13(1), 210-230 (2007)

4. boyd,D., Golder, S. , Lotan, G.: Tweet, Tweet, Retweet: Conversational Aspects of Retweeting on Twitter. HICSS-43. IEEE: Kauai, HI, January 6 (2010)

5. Ellison, N., Steinfield, C., \& Lampe, C. :The benefits of Facebook "friends": Social capital and college students' use of online social network sites. Journal of Computer-Mediated Communication, 12, 1143-1168 (2007)

6. Friedkin, N.E., Johnsen, E.C.: Social Influence Networks And Opinion Change, Friedkin, N. E., \& Johnsen, E. C. 1999. Social influence networks and opinion change. Advances in Group Processes, 16, 1-29, (2009)

7. Huang, Y., Basu, C., Hsu, M. : Exploring motivations of travel knowledge sharing on social networking sites: an empirical investigation of U.S. college students. Journal of Hospitality Marketing \& Management, 19(7), 717-734 (2010)

8. Hui, P.\& Buchegger, S. :Groupthink and Peer Pressure: Social Influence in Online Social Network Groups, Social Network Analysis and Mining, International Conference ASONAM '09, 53-59, (2009)

9. Ioanăs,E., Stoica,I.: Social Media and its Impact on Consumers Behavior, International Journal of Economic Practices and Theories, Vol. 4, No. 2. 295-303 (2014)

10. Jansen, B.J, Zhang, M., Sobel,K. \& Chowdury, A.: Twitter Power:Tweets as ElectronicWord of Mouth,Journal of The American Society For Information Science and Technology, 60(11), 2169-2188, (2009)

11. Kaplan, A., Haenlein, M.: Users of the world, unite: The challenges and opportunities of social media.Business Horizons, 53 (1), 59-68 (2010)

12. Karimi,L., Khodabandelou, R., Ehsani,M., Ahmad, M.: Applying the Uses and Gratifications Theory to Compare Higher nEducation Students' Motivation for Using Social Networking Sites: Experiences from Iran, Malaysia, United Kingdom, and South Africa, Contemporary Educational Technology,5(1), 53-72, (2014)

13. Katz, E., Gurevitch, M., Hass, H.: On the use of mass media for important things. American Sociological Review, 38, 164-181 (1973)

14. Kidd, J.: Enacting Engagement Online: Framing social media use for the museum' in Information, Technology and People. Vol. 24 no1, 64-77 (2011) 
15. Kozinets, R.V., Valck K., Wojnicki A.C., Wilner S. J.S.: Networked Narratives: Understanding Wordof-Mouth Marketing in Online Communities, Journal of Marketing, 74(2), 71-89 (2010)

16. Kwak, H., Lee, C., Park, H., Moon,S.: What is Twitter, a Social Network or a News Media?, International World Wide Web Conference Committee (IW3C2). Raleigh, North Carolina, USA (2010)

17. Li,C.,Owyang,J.: Social marketing analytics, (2010) http://www.webstrategist.com/blog/2010/01/21/socialgraphics-help-you-tounderstand-your-customers-slides-andrecording/

18. Mangold, W.G. \& Faulds, D.J. :Social media: The new hybrid element of the promotion mix, Business Horizons , 52, 357-365, (2009)

19. Neti,S. : Social Media and Its Role in Marketing, International Journal of Enterprise Computing and Business System, Vol. 1 Issue 2,1-15 (2011)

20. Ruggiero, T.: Uses and gratification theory in the 21 st century. Mass Communication \& Society, 3(1), 3-37, (2000)

21. Thoring, A. : Corporate tweeting: analysing the use of Twitter as a marketing tool by UK trade publishers." Publishing research quarterly 27.2 ,141-158 (2011)

22. Tong, C.: Analysis of Some popular Mobile Social Network Systems, TKK T-110.5190 Seminar on Internetworking. (2008)

23. Waad Assaad, J.M. G.: Social Network in marketing (Social Media Marketing) Opportunities and Risks, International Journal of Managing Public Sector Information and Communication Technologies (IJMPICT), Vol. 2, No. 1, 13-22 (2011).

24. Wallach, K. : A Content Analysis of Twitter Use: Factors That Might Increase Music Sales During an Award Show?, The Elon Journal of Undergraduate Research in Communications , Vol. 5, No. 1, 1-2 (2014).

25. Zailskaite-Jakste,L., Kuvykaite, R.: Consumer Engagement in Social Media by Building the Brand, Electronic International Interdisciplinary Conference, 194-202 (2012). 